\title{
A IMPORTÂNCIA DAS RELAÇÕES AFETIVAS NO PROCESSO DE ENSINO E APRENDIZAGEM: UMA PERSPECTIVA INCLUSIVA
}

Ana Mayra Samuel Silva ${ }^{1}$, José Eduardo de Oliveira Evangelista Lanuti ${ }^{2}$, Ana Virginia Isiano Lima ${ }^{1}$, Danielle Aparecida do Nascimento Santos ${ }^{2}$, Janiele de Souza Santos ${ }^{3}$, Denner Dias Barros, Elisa Tomoe Moriya Schlünzen ${ }^{4}$

Universidade Estadual Paulista Júlio de Mesquita Filho - FCT/UNESP, ${ }^{1}$ Curso de Pedagogia, ${ }^{2}$ Mestrado em Educação,

${ }^{3}$ Curso de Matemática, ${ }^{4}$ Professora assistente - autárquica

\section{RESUMO}

A afetividade, conjunto de fenômenos psíquicos que se manifestam em forma de emoções e sentimentos podem ser fundamentais nos processos de ensino e de aprendizagem. A emoção e o intelecto são dimensões inseparáveis do ser humano e essa indissociabilidade deve ser considerada no planejamento e desenvolvimento de atividades pedagógicas. Sendo assim, no decorrer deste artigo será exposta a importância das relações afetivas nos atendimentos pedagógicos realizados junto a Estudantes Público-Alvo da Educação Especial que frequentam o Centro de Promoção para Inclusão Digital, Escolar e Social (CPIDES) da Faculdade de Ciências e Tecnologia (FCT/UNESP). Por meio de uma revisão bibliográfica e com base nos resultados dos atendimentos realizados entre os períodos letivos de 2013 e 2014 foi possível concluir que a importância dada às relações afetivas durante os atendimentos contribuiu para a aprendizagem dos estudantes, considerando a forma como passaram a se relacionar e compreender os conteúdos abordados.

Palavras-chave: Inclusão Escolar, Estudante Público-Alvo da Educação Especial, Processo de Ensino e Aprendizagem, Relações Afetivas.

\section{THE IMPORTANCE OF AFFECTIVE RELATIONS IN THE PROCESS OF TEACHING AND LEARNING: AN INCLUSIVE PERSPECTIVE}

\begin{abstract}
The affection, set of psychic phenomena that manifest themselves in the form of emotions and feelings can be fundamental in the processes of teaching and learning. Emotion and intellect are inseparable dimensions of the human being and this inseparability must be considered in the planning and development of educational activities. Thus, throughout this article will be exposed to the importance of personal relationships in educational attendances at the Target Audience Students attending the Special Education Promotion Centre for Digital Inclusion, Social and School (CPIDES), Faculty of Sciences and Technology (FCT / UNESP). Through a literature review and based on the results of the consultations held between semesters of 2013 and 2014 it was concluded that the importance given to personal relationships during the sessions contributed to student learning, considering the way began to relate and understand the content covered.

Keywords: School Inclusion, Student Target Audience Special Education, Process of Teaching and Learning, Affective Relationships.
\end{abstract}




\section{INTRODUÇÃO E OBJETIVO}

Inclusão é o processo pelo qual, não somente a escola, mas a sociedade, em modo geral, busca valorizar as diferenças entre as pessoas, reconhecendo suas potencialidades, tornando necessária a sua reestruturação e organização, utilizando os mais diversos recursos para o desenvolvimento das pessoas.

Nessa perspectiva, o conceito de inclusão passou a fazer referência não apenas aos Estudantes Público-Alvo da Educação Especial (EPAEE): estudantes com deficiência (Auditiva, Física, Intelectual e Visual), transtornos globais de desenvolvimento e altas habilidades ou superdotação, mas a todos os indivíduos. Sendo assim, tanto escola quanto sociedade devem estar preparados para acolher a todos, respeitando e valorizando as diferenças. Mas para que todos sejam acolhidos e atendidos de acordo com as suas necessidades e especificidades, os objetivos propostos pela inclusão devem estar direcionados a conhecer os estudantes e, por isso, estabelecer relações afetivas com os mesmos.

O "Centro de Promoção para Inclusão Digital, Escolar e Social" (CPIDES) da Universidade Estadual Paulista "Júlio de Mesquita Filho" campus de Presidente Prudente/SP, vinculado ao Grupo de Pesquisa
"Ambientes Potencializadores para Inclusão" (API), desenvolve estudos sobre acessibilidade, estratégias pedagógicas e metodológicas para o uso de recursos tecnológicos com o intuito de trabalhar os aspectos da Educação Especial e da Inclusão Escolar de EPAEE. Nessa perspectiva, as estratégias metodológicas e pedagógicas utilizadas buscam trabalhar não somente conteúdos disciplinares, mas a afetividade, para que ocorra uma formação ampla do indivíduo em relação à aprendizagem de conteúdos e melhoria nas atitudes e convívio com os demais.

No CPIDES são realizados atendimentos $^{1}$ aos EPAEE, onde utilizamos recursos pedagógicos acessíveis como softwares educacionais e objetos de aprendizagem, para a realização de atividades direcionadas de acordo com os interesses dos estudantes, pois o grupo de estagiários atende estudantes com diferentes deficiências e transtornos globais do desenvolvimento, a saber: autismo, paralisia cerebral, deficiência intelectual, síndrome de down, síndrome de sotos, microcefalia, entre outras. Os atendimentos geralmente são realizados individualmente ou em grupo, uma ou duas vezes por semana, no laboratório de informática do CPIDES e na

\footnotetext{
1 Os atendimentos realizados no CPIDES são similares ao Atendimento Educacional Especializado ( $A E E)$, porém não se caracterizam como tal, pelo fato dos estagiários serem discentes de graduação.
} 
Sala de Recursos Multifuncionais (SRM), que são ambientes dotados de equipamentos pedagógicos e tecnológicos, mobiliários e materiais didáticos específicos para 0 trabalho com as deficiências.

Para a realização dos atendimentos é necessário que o estagiário estabeleça com seu estudante um vinculo afetivo e pedagógico, entendendo que esse vínculo é importante para obtenção de resultados satisfatórios no processo de ensino e aprendizagem dos EPAEE. Pois, conforme Bordenave e Pereira (1983, p. 25) apontam, “a aprendizagem é um processo integrado no qual toda pessoa (intelecto, afetividade, sistema muscular) se mobiliza de maneira orgânica”.

A afetividade pode ser compreendida como o conjunto de fenômenos psíquicos que se manifestam em forma de emoções e sentimento. De acordo com Wallon (1968) a afetividade é o vínculo mais forte entre os indivíduos. Portanto, faz parte da base do processo educacional e está voltada para a formação total do ser humano. O autor ainda enfatiza que os professores devem repensar a prática escolar a fim de dar maior valor à dimensão afetiva no processo de ensino e de aprendizagem. Na relação entre professor e estudante as expressões afetivas positivas podem favorecer a aprendizagem, enquanto as expressões afetivas negativas podem criar obstáculos tanto para o ensino quanto para o ato de aprender.

Conforme Bercht (2001, p. 59),

a afetividade pode ser conceituada como todo o domínio das emoções, dos sentimentos das emoções, das experiências sensíveis e, principalmente, da capacidade de entrar em contato com sensações, referindo-se às vivências dos indivíduos e às formas de expressão mais complexas e essencialmente humanas.

Com essas perspectivas, o presente trabalho tem por objetivo apresentar os elementos que compuseram o estabelecimento de uma relação afetiva nos atendimentos realizados junto a EPAEE no CPIDES.

\section{MÉTODO}

O método adotado tem uma abordagem qualitativa, realizada mediante a observação e análise dos dados coletados nos atendimentos e revisão teórica e bibliográfica a partir da leitura de referenciais teóricos que fundamentam os temas presentes nos atendimentos. Conforme Richardson (1999) a abordagem qualitativa, além de ser uma opção metodológica do investigador, também é uma forma adequada para entender a natureza de um fenômeno social. 
De acordo com Lüdke e André (1986, p. 26), "a observação possibilita um contato pessoal e estreito do pesquisador com 0 fenômeno pesquisado", e por isso foram analisadas as atividades de planejamento, execução e avaliação dos atendimentos realizados no CPIDES, para compreender como o vínculo afetivo contribui para um desenvolvimento dos EPAEE atendidos.

Com o intuito de desenvolver atividades de ensino, pesquisa e extensão, e divulgar os dados obtidos, o grupo de pesquisa API se submeteu ao Comitê de Ética em Pesquisa (CEP), sendo o protocolo de aprovação: 106/2009.

Dessa forma, a análise dos atendimentos será abordada no item a seguir.

\section{DISCUSSÃO}

Aksu (1991) destacou em suas pesquisas que o professor que ajuda seus estudantes a terem confiança, faz com que os mesmos demonstrem prazer em aprender, ao mesmo tempo em que professores com atitudes positivas possibilitam a independência aos seus estudantes diante de um desafio.

As emoções têm um papel fundamental no processo de ensino e de aprendizagem, pois podem facilitar ou dificultar todo o processo, pois "o ensino e a aprendizagem não acontece em um âmbito isolado e neutro, mas dependem do contexto no qual se ensina e do comportamento humano dos participantes." (CHACÓN, 2003, p.147)

Para trabalhar as emoções e a afetividade, no direcionamento das atividades pedagógicas do CPIDES é inicialmente priorizada a intencionalidade de constituição de uma relação amigável com os estudantes e familiares, a fim de trabalhar com a sua motivação e consequentemente facilitar a comunicação e o diálogo. Ao iniciar os atendimentos, que ocorrem uma vez por semana durante uma hora, há sempre uma conversa sobre vivências cotidianas dos estudantes, onde é realizada uma entrevista com perguntas geradoras sobre o que fez durante a semana que se passou, como está indo sua aprendizagem na escola regular ou na Instituição Especializada que frequência, bem como no Atendimento Educacional Especializado (AEE). Além disso, na entrevista são contempladas perguntas sobre seus amigos e familiares, entre outros assuntos de interesse dos mesmos.

A entrevista inicial é de suma importância para que o trabalho pedagógico seja estruturado, pois mediante as perguntas sobre o cotidiano do estudante o estagiário fica mais próximo, auxiliando em questões particulares que podem influir no processo de aprendizagem, visto que com isso é estabelecido um vinculo afetivo. 
Antes do término dos atendimentos, após o encerramento das atividades pedagógicas propostas, os estudantes têm a oportunidade de mais uma vez conversar ou pesquisar coisas que fazem parte do seu cotidiano, como por exemplo, acessar jogos na internet, realizar pesquisas escolares, ouvir músicas, assistir vídeos, entre outros assuntos. Por meio desse hábito o vínculo afetivo entre estagiário e estudante se estreita, uma vez que ambos passam a conhecer mais um sobre o outro.

Todas as atividades desenvolvidas com os EPAEE no CPIDES visam atingir o patamar de um ambiente Construcionista, Contextualizado e Significativo (CCS), que, conforme Schlünzen,

É um ambiente favorável que desperta o interesse do aluno e o motiva a explorar, a pesquisar, a descrever, a refletir, a depurar as suas ideias. [...] As informações que são significativas para o aluno podem ser transformadas em conhecimento [...] O aluno consegue descobrir a relação com tudo que está aprendendo, a partir de seus interesses individuais dentro do seu contexto. (2000, p. 82)

Levando em consideração os aspectos supracitados, pode-se concluir que os estímulos pedagógicos gerados aos EPAEE que frequentam os atendimentos no CPIDES, partem de seus próprios interesses e dificuldades, o que tornam as atividades mais prazerosas, pois passam a despertar a atenção, proporcionando a construção de sua autonomia, o estabelecimento de vínculos sócio-afetivos e potencialização de suas habilidades desenvolvidas.

\section{RESULTADOS}

Por meio das atividades desenvolvidas nos atendimentos, pode-se perceber claramente o avanço dos estudantes: se socializam com maior facilidade, se preocupam em realizar as tarefas propostas, interagem com o estagiário, perguntam, refletem sobre o que fizeram, demonstram sua satisfação ou insatisfação em realizar as atividades. Embora seja um processo lento, os avanços são perceptíveis com todos os estudantes atendidos.

O caso da estudante aqui denominada "Jordana" (nome fictício), por exemplo, permite comprovar que por meio do atendimento realizado no CPIDES, com atividades direcionadas às suas necessidades foi possível promover sua autonomia por meio das relações afetivas estabelecidas entre professor e estudante. No início das atividades, em 2013, a estudante demonstrou-se tímida, não interagia com a estagiária que realiza os atendimentos e nem com os demais estudantes, realizava as tarefas sem refletir sobre o conteúdo 
abordado e não solicitava ajuda nem quando necessário. Afetivamente esta estudante não estava satisfeita, pois o vinculo afetivo e pedagógico entre a nova estagiária e ela, ainda não havia sido estabelecido.

No decorrer as atividades e do período letivo, a partir do vinculo afetivo já estabelecido, a mesma passou a demonstrar uma intenção de relacionar com as pessoas, realizando as atividades com maior facilidade, questionando e sugerindo novos temas a serem abordados nos atendimentos (Figura 1). Atualmente a estudante e a estagiária estabeleceram uma relação amigável, o que colaborou muito no processo de ensino e aprendizagem.

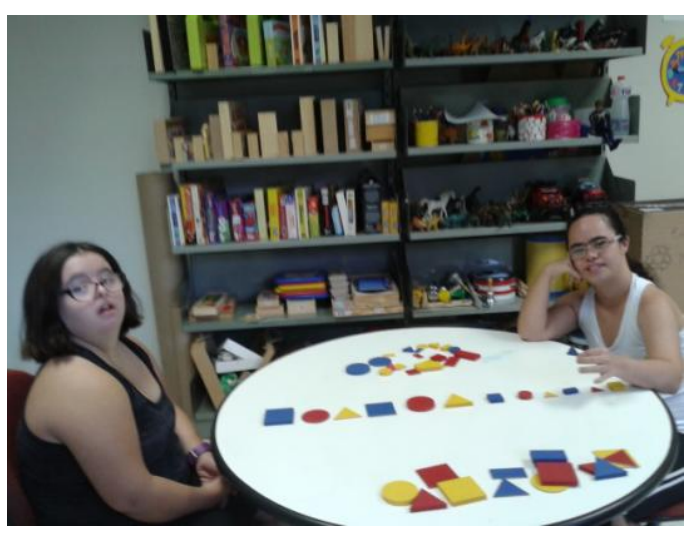

Figura 1. Estudantes J e A interagindo durante um atendimento.

A estudante "Antonia", iniciou suas atividades no CPIDES em abril de 2014, e desde o princípio sempre se mostrou participativa, interativa e animada. Portanto, o vínculo afetivo a ser estabelecido com essa estudante foi praticamente instantâneo, sendo que a mesma tem facilidade para estabelecer relações amigáveis.

A fim de que os estudantes do CPIDES se socializem mais, são promovidas duas festas de confraternização ao ano, e diversas atividades coletivas. Nesses acontecimentos (Figura 2), é notório que os estudantes interagem entre si, algo que não é muito comum no dia-a-dia devido os atendimentos serem realizados individualmente uma vez por semana. 


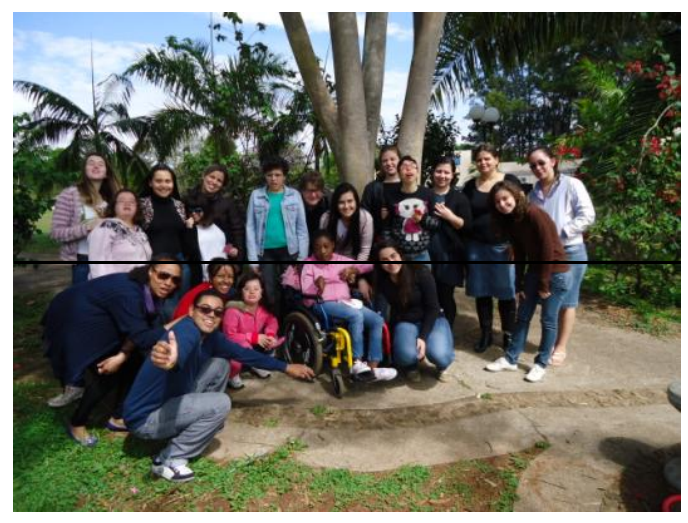

Figura 2. Estudantes e Estagiários reunidos em um Piquenique.

Segundo Santos (2006, p. 105), na teoria Vygotskyana,

O sujeito constrói suas formas de ação e sua consciência nas relações sociais, ou seja, a ação do sujeito é considerada a partir da ação entre os sujeitos. Ao examinar os modos de participação do outro no funcionamento do sujeito, afirma que as relações são caracterizadas por uma grande reciprocidade, por isto 0 papel fundamental do professor enquanto mediador e estimulado, lançando desafios.

Em uma perspectiva de educação especial na perspectiva da educação inclusiva, em que cada indivíduo deve participar das atividades para 0 desenvolvimento de suas potencialidades com vistas aos seus interesses e objetivos, 0 professor necessita estabelecer vínculos afetivos para que consiga detectar as dificuldades dos estudantes, partindo do que ele já sabe, para que as atividades tornem-se significativas. Relações afetivas como diálogo, por exemplo, facilitam esse diagnóstico e aproxima professor e estudante facilitando o processo de aprendizagem.

Com isso, o estudante torna-se mais amigável, confiante, presta mais atenção nos conteúdos que estão sendo abordado durante os atendimentos realizados, o que alimenta o anseio pelo saber e o torna mais autônomo, quebrando, por muitas vezes, as barreiras estabelecidas pela não aceitação do processo de inclusão escolar. Contudo, devemos levar em consideração que cada ser é único, e as situações, interesses e objetivos são particulares em sua especificidade, não perdendo a essência do trabalho pedagógico.

A partir dos resultados que estão sendo obtidos no decorrer dos atendimentos realizados no CPIDES, pode-se concluir que o vínculo afetivo deve ser estabelecido antes de qualquer trabalho realizado com EPAEE, pois a emoção e o intelecto são dimensões inseparáveis do ser humano. 


\section{CONCLUSÃO}

No processo de ensino e de aprendizagem de EPAEE é necessário que sejam estimulados a curiosidade e o interesse em aprender para construir o conhecimento, bem como construir valores necessários para a sua inclusão social. Ao refletirmos sobre as atividades propostas nos atendimentos realizados no CPIDES podemos verificar os avanços significativos em diversos aspectos dos sujeitos, principalmente relacionados à sua autonomia e relações afetivas com seus pares. Os resultados correspondem à proposta do grupo de pesquisa, de que todos são capazes de aprender (ainda que em tempos e de formas distintas) se tiverem suas potencialidades desenvolvidas através de atividades significativas e direcionadas à sua realidade, interesses e objetivos.

\section{REFERÊNCIAS}

AKSU, M. A longitudinal study on attitudes toward mathematics by departamente and sex at the Universy level. School Science and Mathematics, v.91n n.5, p.185-192, 1991. http://dx.doi.org/10.1111/j.19498594.1991.tb12077.x

BERCHT, M. Em direção a agentes pedagógicos com dimensões afetivas. 2001. Tese (Doutorado) - Instituto de Informática, Universidade Federal do Rio Grande do Sul, Porto Alegre - RS.

BORDENAVE, J. D.; PEREIRA, A. M. Estratégias de ensino-aprendizagem. Petrópolis: Vozes, 1983.
CHACÓN, I. M. G. Matemática emocional: os afetos na aprendizagem matemática. Porto Alegre: Artmed, 2003.

LÜDKE, M.; ANDRÉ, M. E. D. A. Pesquisa em educação: abordagens qualitativas. São Paulo: EPU, 1986.

RICHARDSON, R. J. et al. Pesquisa social: métodos e técnicas. São Paulo: Atlas, 1999.

SANTOS, D. A. N. A formação de professores de uma escola da rede pública estadual em serviço para o trabalho com projetos utilizando as tecnologias de informação e comunicação. 2006. 183f. Dissertação (Mestrado em Educação) - Universidade Estadual Paulista, Presidente Prudente - SP.

SCHLÜNZEN, E. T. M. Mudanças nas práticas pedagógicas do professor: criando um ambiente construcionista, contextualizado e significativo para crianças com necessidades especiais físicas. 2000. 252f. Tese (Doutorado em Educação) - Pontifícia Universidade Católica de São Paulo, São Paulo - SP.

WALLON, H. A evolução psicológica da criança. Lisboa: Edição 70, 1968.

Recebido para publicação em 11/08/2014

Revisado em 24/08/2014

Aceito em 09/09/2014 